\title{
Composição corporal e exigências nutricionais em magnésio, potássio e sódio de cordeiros Santa Inês(1)
}

\author{
Luciana Castro Geraseev(2), Juan Ramón Olalquiaga Pérez ${ }^{(2)}$, Cristiane Leal dos Santos ${ }^{(2)}$, \\ Osni Vieira Prado $^{(2)}$ e Kleber Tomás de Resende ${ }^{(3)}$
}

\begin{abstract}
Resumo - O trabalho objetivou determinar a composição corporal de cordeiros Santa Inês e estimar suas exigências de magnésio, potássio e sódio, para ganho de peso. Foram conduzidos dois experimentos com 18 cordeiros machos em cada um, com peso médio inicial de 25 e $15 \mathrm{~kg}$ no primeiro e no segundo experimentos, respectivamente. Em cada experimento, seis animais foram abatidos, para determinação das quantidades de cada mineral retido no corpo, servindo como animais-referência para a técnica do abate comparativo. Os doze animais remanescentes em cada experimento foram divididos em dois grupos: seis animais receberam alimentação ad libitum e seis receberam alimentação restrita. Os cordeiros do grupo ad libitum e restrito foram abatidos quando os do grupo ad libitum atingiram 35 e $25 \mathrm{~kg}$ de peso vivo no primeiro e segundo experimentos, respectivamente. A composição corporal em $\mathrm{Ca}, \mathrm{P}, \mathrm{Mg}$, $\mathrm{K}$ e $\mathrm{Na}$ foi estimada a partir de equações de regressão do logaritmo da quantidade desses minerais presentes no corpo vazio dos animais, em razão do peso corporal vazio. As exigências líquidas desses minerais por kg de ganho de peso vivo, obtidas a partir da derivação das equações de predição da composição corporal foram: 0,47 e $0,41 \mathrm{~g}$ de $\mathrm{Mg}, 2,32$ e 2,05 g de K e 1,33 e 0,55 g de Na, respectivamente, em animais com 15 e $35 \mathrm{~kg}$.
\end{abstract}

Termos para indexação: Ovis aries, ovinos, necessidade de nutrientes, nutrientes minerais.

\section{Body composition and nutritional requirements for magnesium, potassium and sodium} of Santa Inês lambs

\begin{abstract}
This study was carried out in order to determine body composition in magnesium, potassium and sodium requirements for weight gain in Santa Inês lambs. Two experiments were conducted using 18 animals in each one: in the first experiment, animals with mean initial live weight of $25 \mathrm{~kg}$ were used; in the second, animals with initial live weight of $15 \mathrm{~kg}$ were used. Six animals were slaughtered at the beginning of each experiment, in order to determine the amount of each mineral retained in the animals' body, as check animals for comparative slaughter technique. The remaining twelve animals were divided in two groups: six animals were ad libitum fed and six animals were restrictedly fed. The animals ad libitum and restrictedly fed were slaughtered when the first reached 35 and $25 \mathrm{~kg}$ of live weight, in the first and in the second experiments, respectively. Their body composition was estimated through the prediction equations obtained from the regression of the logarithm of the amount of $\mathrm{Mg}, \mathrm{K}$, and $\mathrm{Na}$ in the empty body on the logarithm of the empty body weight. The net requirements for gain were obtained through derivation of the body composition prediction equation. Net requirements of $\mathrm{Mg}, \mathrm{K}$ and $\mathrm{Na}$ for $\mathrm{kg}$ of live weight gain for lambs with 15 and $35 \mathrm{~kg}$ of live weight were, respectively: 0.47 and $0.41 \mathrm{~g}$ of $\mathrm{Mg} ; 2.32$ and $2.05 \mathrm{~g}$ of $\mathrm{K} ; 1.33$ and $0.55 \mathrm{~g}$ of $\mathrm{Na}$.
\end{abstract}

Index terms: Ovis aries, sheep, nutritional requirements, mineral nutrients.

\footnotetext{
(1) Aceito para publicação em 21 de julho de 2000.

(2) Universidade Federal de Lavras (UFLA), Dep. de Zootecnia, Caixa Postal 37, CEP 37200-000 Lavras, MG E-mail: lgerasev@ufla.br, jroperez@ufla.br, msccii@ufla.br

(3) Universidade Estadual Paulista (UNESP), Campus de Jaboticabal, Rod. Carlos Tonanni, km 5, CEP 14870-000 Jaboticabal, SP

E-mail: kresende@fcav.unesp.br
}

Introdução

Os elementos minerais constituem 2 a $5,5 \%$ do corpo dos animais vertebrados; mas, dada a diversidade de funções que exercem no organismo, são importantes em todo o campo da bioquímica nutricional (Georgievskii, 1982; Dayrell, 1993). 
Representam um componente essencial na dieta de ruminantes e influenciam de modo marcante a sua produtividade, pois atuam como co-fatores essenciais para utilização de energia e proteína. Além disso, esses elementos inorgânicos não podem ser sintetizados pelo organismo animal, devendo ser fornecidos de forma balanceada na alimentação diária (Beede, 1991).

A importância de se fornecer, aos animais, suplementação mineral adequada, torna-se ainda mais evidente em vista do empobrecimento dos solos, resultando em forrageiras deficientes em um grande número de macro e micro elementos minerais (Andriguetto et al., 1990).

Deficiências ou excessos de minerais podem causar problemas reprodutivos, perda de peso, desordem de pele, diarréia, anemia, perda de apetite, anormalidade óssea, entre outros (Conrad et al., 1985). McDowell (1985) assinalou que diversas investigações realizadas na América Latina reportaram aumentos de 20 a $100 \%$ nas porcentagens de parição, de 10 a $25 \%$ nas taxas de crescimento e sensível redução dos índices de mortalidade como resultado da adoção da suplementação mineral em bovinos.

Assim, o conhecimento das exigências nutricionais é de suma importância para a exploração racional de qualquer atividade. Entretanto, no Brasil, ainda existem poucos estudos sobre esse assunto, principalmente no caso de ovinos deslanados e, especificamente, da raça Santa Inês.

$\mathrm{Na}$ maioria dos casos, os cálculos para balanceamento de ração para estes animais têm sido baseados nas tabelas do National Research Council (NRC) e do Agricultural Research Council (ARC). Essas recomendações têm sido usadas sem qualquer preocupação de examiná-las e adaptá-las às condições locais, existindo dúvidas quanto à validade do uso de requerimentos estabelecidos nas regiões temperadas para animais em regiões tropicais (Silva, 1996). Os experimentos de alimentação podem ser usados para estimar as exigências de minerais, mas eles só prevalecem nas condições em que o experimento foi conduzido. Por esses motivos, muitos países têm desenvolvido tabelas de exigências nutricionais adaptadas às suas condições e ao tipo de animais utilizados.

O objetivo deste trabalho foi determinar a composição corporal de cordeiros Santa Inês e suas exigências nutricionais em magnésio, potássio e sódio.

\section{Material e Métodos}

O trabalho foi desenvolvido no setor de Ovinocultura do Departamento de Zootecnia da Universidade Federal de Lavras, em Lavras, região sul do Estado de Minas Gerais. Foram conduzidos dois experimentos, utilizando-se 18 cordeiros machos inteiros da raça Santa Inês em cada um.

O primeiro experimento foi realizado no período de fevereiro a julho de 1997, em que foram avaliadas a composição corporal e as exigências nutricionais em magnésio, potássio e sódio, de cordeiros na faixa de 25 a $35 \mathrm{~kg}$ de peso vivo. O segundo experimento foi realizado no período de setembro de 1997 a março de 1998, sendo avaliados os mesmos parâmetros descritos em relação ao primeiro experimento, com cordeiros na faixa de 15 a $25 \mathrm{~kg}$ de peso vivo.

No início do experimento, seis animais foram abatidos servindo como animais-referência; os demais entraram no experimento aos pares, sendo um para alimentação ad libitum, e o outro, para alimentação restrita. Os animais da alimentação ad libitum receberam quantidades de ração que permitiam uma sobra de $20 \%$ do total oferecido, enquanto os animais do grupo de alimentação restrita receberam quantidades de ração para atender a uma ingestão diária de energia metabolizável, correspondendo à exigência de mantença, com acréscimo de $20 \%$, segundo as recomendações do Agricultural Research Council (1988).

A dieta experimental (Tabela 1) foi balanceada para atender às exigências nutricionais de proteína, energia metabolizável e minerais, segundo as recomendações do Agricultural Research Council (1988), sendo fornecida duas vezes ao dia, às $8 \mathrm{e}$ às 16 horas. $\mathrm{O}$ controle do consumo foi medido por meio da pesagem das quantidades fornecidas e rejeitadas diariamente. Amostras da dieta experimental e das sobras foram coletadas diariamente e, posteriormente, a cada 14 dias, formaram-se amostras compostas por animal. O controle do desenvolvimento dos animais foi feito por meio de pesagens semanais sem jejum prévio.

Quando os animais que recebiam alimentação ad libitum atingiram o peso pré-determinado para o abate, $35 \mathrm{~kg}$ e $25 \mathrm{~kg}$ no primeiro e segundo experimento, respectivamente, foram abatidos juntamente com o seu par da alimentação restrita.

Antes de serem abatidos, os animais foram submetidos a um jejum de 16 horas, com acesso a água. $\mathrm{O}$ abate foi feito por sangramento através do corte da carótida e jugular dos animais, sendo o sangue coletado, pesado e congelado para análises posteriores. Após a coleta do sangue, retirou-se o trato digestivo, bexiga e vesícula biliar, sendo seus conteúdos eliminados para determinação do peso cor- 
Tabela 1. Composição da dieta experimental, expressa em porcentagem da matéria seca, oferecida a ovinos Santa Inês.

\begin{tabular}{|c|c|c|c|c|c|c|c|c|}
\hline Ingrediente & $\begin{array}{c}\text { Matéria seca } \\
(\%)\end{array}$ & $\begin{array}{c}\text { Energia } \\
\text { metabolizável }^{(1)} \\
(\mathrm{kcal} / \mathrm{kg})\end{array}$ & $\begin{array}{c}\text { Proteína } \\
\text { bruta }(\%)\end{array}$ & $\mathrm{Ca}(\%)$ & $\mathrm{P}(\%)$ & $\mathrm{Na}(\%)$ & $\operatorname{Mg}(\%)$ & $\mathrm{K}(\%)$ \\
\hline Milho, grão & 66,23 & 2,087 & 6,49 & 0,022 & 0,196 & 0,023 & 0,060 & 0,230 \\
\hline Farelo de soja & 12,37 & 0,394 & 6,28 & 0,053 & 0,097 & 0,005 & 0,030 & 0,223 \\
\hline Feno Coast Cross & 20,25 & 0,395 & 2,44 & 0,120 & 0,080 & 0,008 & 0,041 & 0,362 \\
\hline Calcário & 0,85 & - & - & 0,306 & - & - & - & - \\
\hline Sal comum & 0,25 & - & - & - & - & 0,092 & - & - \\
\hline Sup. mineral ${ }^{(2)}$ & 0,01 & - & - & - & - & - & - & - \\
\hline Sup. vitamínico ${ }^{(2)}$ & 0,04 & - & - & - & - & - & - & - \\
\hline Total & 100,00 & 2,876 & 15,21 & 0,501 & 0,373 & 0,128 & 0,131 & 0,815 \\
\hline
\end{tabular}

(1)National Research Council (1985). (2)Suplemento mineral e vitamínico (nutriente/kg de suplemento): Vit. A, 2.500.000 UI; Vit. D3, 500.000 UI; Vit. E, $3.000 \mathrm{mg}$; Tiamina, $750 \mathrm{mg}$; Riboflavina, $1.000 \mathrm{mg}$; Vit. B12, $2.800 \mathrm{mcg}$; Niacina, $500 \mathrm{mg}$; selênio, $150 \mathrm{mg}$; iodo, $1.000 \mathrm{mg}$; cobalto, $600 \mathrm{mg}$; ferro, $35.000 \mathrm{mg}$; cobre, $20.000 \mathrm{mg}$; manganês, $49.000 \mathrm{mg}$; zinco, $75.000 \mathrm{mg}$.

poral vazio. O corpo do animal (subdividido em partes menores), bem como o aparelho digestivo, vísceras, sangue, cabeça, patas e pele foram acondicionados em sacos de plástico e congelados. Posteriormente, este material congelado foi cortado e moído, para a retirada das amostras para as análises químicas.

O abate dos animais do grupo de referência e o processamento das amostras referentes ao corpo destes animais seguiram esses mesmos procedimentos.

As análises químicas foram efetuadas segundo o método descrito por Silva (1990). As amostras referentes ao corpo dos animais foram secadas em estufa com circulação de ar, a $65^{\circ} \mathrm{C}$, por 72 horas. Após a secagem, esse material foi desengordurado em aparelho Soxhlet e triturado em moinho de bola.

As análises dos minerais foram feitas por meio da digestão nitroperclórica das amostras do corpo dos animais, obtendo-se, dessa forma, a solução mineral. A partir desta solução, foram feitas diluições, para determinação dos diferentes minerais. Quanto ao $\mathrm{Mg}$, as diluições foram feitas adicionando-se cloreto de estrôncio, e as leituras, tomadas em espectrofotômetro de absorção atômica. As diluições do $\mathrm{Na}$ e $\mathrm{K}$ foram feitas com nitrato de lítio, e as leituras, tomadas em espectrofotômetro de chama.

O conteúdo corporal de $\mathrm{Mg}, \mathrm{Na}$ e $\mathrm{K}$ foi determinado em razão da concentração destes minerais nas amostras do corpo de todos os animais. A partir destes dados, foram obtidas equações de predição da composição corporal em termos de macrominerais. Estas equações foram obtidas por meio da equação de regressão do logaritmo da quantidade do mineral presente no corpo vazio em função do logaritmo do peso de corpo vazio (Agricultural Research Council, 1988).

Para composição do ganho em peso, utilizou-se a técnica do abate comparativo descrita pelo Agricultural Research Council (1988), a qual possibilita a determinação mediante a diferença entre o total de cada mineral retido no corpo vazio dos animais abatidos com 35 e $25 \mathrm{~kg}$ de peso vivo em relação ao total de cada mineral retido no corpo vazio dos animais referência em cada um dos experimentos.

As exigências líquidas de minerais para o ganho em peso corporal vazio foram estimadas a partir da derivação das equações de predição da composição corporal.

A conversão das exigências líquidas para o ganho em peso corporal vazio para exigências líquidas para o ganho em peso vivo foi obtida utilizando-se o fator resultante da regressão do quociente $\mathrm{PV} / \mathrm{PCV}$ dos animais em razão do seu peso corporal vazio. Para o cálculo das exigências dietéticas totais, foram utilizados os valores de perdas endógenas e disponibilidade, utilizados pelo Agricultural Research Council (1988).

O período experimental não teve duração prefixada, pois correspondeu ao período necessário para que os animais da alimentação ad libitum atingissem o peso vivo de 35 e $25 \mathrm{~kg}$ no primeiro e segundo experimentos, respectivamente. $\mathrm{O}$ delineamento experimental foi inteiramente casualizado, sendo feita a análise de regressão das quantidades dos macrominerais presentes no corpo vazio em razão do peso vivo para obtenção das equações de predição.

O modelo estatístico utilizado foi: $\mathrm{Y}_{\mathrm{ij}}=\mu+\mathrm{b}_{1} \mathrm{x}_{1 \mathrm{i}}+\mathrm{e}_{\mathrm{ij}}$, onde: $Y_{i j}=$ logaritmo da quantidade de macromineral presente no corpo vazio; $\mu=$ efeito da média; $b_{1}=$ coeficiente de regressão; $\mathrm{x}_{1 \mathrm{i}}=$ logaritmo do peso do corpo vazio; $\mathrm{e}_{\mathrm{ij}}=$ erro aleatório.

\section{Resultados e Discussão}

\section{Composição corporal}

Nos dois experimentos, ocorreu um aumento na concentração de matéria seca e gordura corporal em razão do aumento do peso vivo; por outro lado, ocorreram decréscimos nas concentrações de proteína e dos três minerais no corpo vazio dos animais (Tabela 2). 
Tabela 2. Peso e composição do corpo vazio para os animais de referência, de alimentação restrita e ad libitum, em ovinos Santa Inês.

\begin{tabular}{lccc}
\hline Peso e composição & Referência & $\begin{array}{c}\text { Alimentação } \\
\text { restrita }\end{array}$ & $\begin{array}{c}\text { Alimentação } \\
\text { ad libitum }\end{array}$ \\
\hline & \multicolumn{3}{c}{ Animais de 15 a $25 \mathrm{~kg}$ de peso vivo } \\
Peso vivo (kg) & $15,02 \pm 0,614$ & $14,50 \pm 0,774$ & $24,92 \pm 0,664$ \\
Peso corporal vazio (kg) & $12,90 \pm 1,143$ & $12,65 \pm 1,367$ & $21,91 \pm 1,384$ \\
Matéria seca (\%) & $32,36 \pm 3,034$ & $34,53 \pm 1,580$ & $35,91 \pm 1,227$ \\
Proteína (\% mat. natural) & $17,52 \pm 0,736$ & $17,93 \pm 0,738$ & $17,14 \pm 0,942$ \\
Gordura (\% mat. natural) & $10,02 \pm 3,084$ & $12,17 \pm 1,506$ & $14,43 \pm 0,985$ \\
Magnésio (\% mat. natural) & $0,060 \pm 0,007$ & $0,059 \pm 0,008$ & $0,057 \pm 0,008$ \\
Potássio (\% mat. natural) & $0,294 \pm 0,010$ & $0,290 \pm 0,011$ & $0,278 \pm 0,015$ \\
Sódio (\% mat. natural) & $0,183 \pm 0,010$ & $0,183 \pm 0,007$ & $0,165 \pm 0,006$ \\
\hline & Animais de 25 a 35 kg de peso vivo \\
Peso vivo (kg) & $24,31 \pm 0,976$ & $26,52 \pm 1,763$ & $34,80 \pm 0,748$ \\
Peso corporal vazio (kg) & $20,60 \pm 1,308$ & $23,18 \pm 1,678$ & $30,06 \pm 1,095$ \\
Matéria seca (\%) & $36,84 \pm 2,696$ & $39,60 \pm 1,390$ & $40,15 \pm 2,668$ \\
Proteína (\% mat. natural) & $19,24 \pm 1,962$ & $18,38 \pm 0,957$ & $18,20 \pm 0,909$ \\
Gordura (\% mat. natural) & $13,86 \pm 2,806$ & $17,17 \pm 1,168$ & $18,62 \pm 2,180$ \\
Magnésio (\% mat. natural) & $0,058 \pm 0,004$ & $0,054 \pm 0,004$ & $0,052 \pm 0,002$ \\
Potássio (\% mat. natural) & $0,288 \pm 0,058$ & $0,272 \pm 0,043$ & $0,257 \pm 0,038$ \\
Sódio (\% mat. natural) & $0,106 \pm 0,008$ & $0,101 \pm 0,007$ & $0,091 \pm 0,012$ \\
\hline
\end{tabular}

Esse decréscimo na concentração desses minerais pode ser explicado pelo aumento na concentração de gordura, e, no caso do $\mathrm{Mg}$, pela redução do crescimento ósseo à medida que aumenta o peso vivo dos animais. Segundo Nour \& Thonney (1988) e Williams et al. (1983), existe correlação negativa entre o teor de gordura corporal e o teor dos elementos inorgânicos, uma vez que a concentração desses elementos nos depósitos de gordura é mínima. Vários autores também encontraram valores decrescentes para a concentração corporal destes minerais (Grace, 1983; Thompson et al., 1988; Resende, 1989; Pires et al., 1993; Ferreira et al., 1998; Paulino et al., 1999; Signoretti et al., 1999). Todavia, o Agricultural Research Council (1988) considera constante a deposição desses minerais, e estima as seguintes concentrações corporais: $0,41 \mathrm{~g}$ de $\mathrm{Mg}, 1,80 \mathrm{~g}$ de $\mathrm{K}$ e $1,10 \mathrm{~g} \mathrm{de} \mathrm{Na/kg} \mathrm{de} \mathrm{peso} \mathrm{corporal} \mathrm{vazio.}$

Os valores de concentração de $\mathrm{K}$ encontrados nesta pesquisa foram maiores que os estimados pelo Agricultural Research Council (1988): 1,8 g/kg de PCV. Este fato indica, possivelmente, que os animais utilizados neste estudo apresentaram uma proporção de músculos, gordura e ossos diferente em relação aos dos animais utilizados nos estudos analisados pelo Agricultural Research Council (1988). Isto pode ser explicado pelo fato de que nos trabalhos analisados por esse comitê foi utilizada uma grande porcenta- gem de animais castrados e de raças de origem e estrutura diferente da raça deslanada utilizada nos presentes experimentos.

A partir da composição corporal dos animais em $\mathrm{Mg}, \mathrm{K}$ e $\mathrm{Na}$ e respectivos peso vivo e peso corporal vazio, foram determinadas as equações de predição da composição corporal destes minerais (Tabela 3 ).

Para determinação destas equações, foi realizada uma análise de comparação de equações lineares (Snedecor \& Cochran, 1967) entre as equações de predição estimadas com os animais referência e ad libitum, comparada com as equações estimadas com todos animais, uma vez que na literatura consultada foram encontrados alguns trabalhos em que as equações de predição da composição corporal foram estimadas excluindo-se os animais da alimentação restrita (Pires et al., 1993; Paulino et al., 1999).

Os resultados desta análise mostraram não haver diferenças significativas entre as duas equações, e portanto para a predição da composição corporal desses minerais, foram utilizadas as equações obtidas com todos os animais, em ambos os experimentos.

Com exceção da equação geral obtida para o sódio, os valores dos coeficientes de determinação encontrados para as demais equações listadas na Tabela 3 foram significativos $(P<0,01)$, e mostram que houve um ótimo ajustamento das equações, com baixa dispersão dos dados em torno da linha de regressão.

Para obtenção das equações gerais de cada mineral, também foi realizada uma análise de compara-

Tabela 3. Equações de regressão para o peso de corpo vazio $(\mathrm{g})$, em razão do peso vivo $(\mathrm{g})$, e para a quantidade dos nutrientes presentes no corpo vazio em razão do peso corporal vazio (PCV), em ovinos Santa Inês.

\begin{tabular}{|c|c|c|}
\hline Item & Equação & $\mathrm{R}^{2}(\%)$ \\
\hline \multicolumn{3}{|c|}{ Animais de 15 a $25 \mathrm{~kg}$} \\
\hline Peso (g) & $\mathrm{PCV}=-671,20+0,9089 \mathrm{PV}$ & 96,68 \\
\hline Magnésio (g) & $\log M g=-3,05216+0,957203 \log P C V$ & 82,36 \\
\hline Potássio (g) & $\log K=-2,16125+0,909001 \log P C V$ & 97,55 \\
\hline Sódio $(\mathrm{g})$ & $\log \mathrm{Na}=-1,87763+0,790907 \log$ PCV & 97,18 \\
\hline \multicolumn{3}{|c|}{ Animais de 25 a $35 \mathrm{~kg}$} \\
\hline Peso (g) & $\mathrm{PCV}=-1291,62+0,900859 \mathrm{PV}$ & 96,82 \\
\hline Magnésio (g) & $\log M g=-2,24424+0,767345 \log P C V$ & 79,02 \\
\hline Potássio (g) & $\log K=-1,67980+0,796819 \log P C V$ & 43,88 \\
\hline Sódio $(\mathrm{g})$ & $\log \mathrm{Na}=-1,53535+0,665291 \log \mathrm{PCV}$ & 59,22 \\
\hline \multicolumn{3}{|c|}{ Geral } \\
\hline Magnésio (g) & $\log \mathrm{Mg}=-2,68265+0,868077 \log$ PCV & 88,97 \\
\hline Potássio (g) & $\log \mathrm{K}=-1,98586+0,866839 \log \mathrm{PCV}$ & 86,39 \\
\hline Sódio $(\mathrm{g})$ & $\log \mathrm{Na}=0,39276+0,236604 \log \mathrm{PCV}$ & 15,85 \\
\hline
\end{tabular}


ção de equações lineares (Snedecor \& Cochran, 1967) entre as equações de predição para os animais com 15 a $25 \mathrm{~kg}$ de peso vivo (equação 1 ) e as equações de predição para animais com 25 a $35 \mathrm{~kg}$ de peso vivo (equação 2).

Quanto ao $\mathrm{Mg}$ e $\mathrm{K}$, os resultados desta análise demonstraram não haver diferenças entre as equações 1 e 2; portanto, seria possível a utilização de qualquer uma das equações para a predição da composição corporal em $\mathrm{Mg}$ e $\mathrm{K}$ de animais com peso vivo na faixa de 15 aos $35 \mathrm{~kg}$.

No caso do $\mathrm{Na}$, o coeficiente de determinação da equação geral foi baixo, o que demonstra que não houve um bom ajustamento desta equação. Além disso, na análise de comparação de equações lineares, foi encontrada diferença no coeficiente de elevação entre as equações 1 e 2 . Portanto, para o $\mathrm{Na}$, a extrapolação de uma das equações (1 ou 2) para a faixa dos 15 aos $35 \mathrm{~kg}$ de peso vivo não seria recomendável.

Essa diferença na composição corporal em $\mathrm{Na}$, encontrada entre os dois experimentos, pode ter sido devida às diferenças nas épocas em que os experimentos foram conduzidos. Sendo, este mineral, perdido pela transpiração, mudanças nas condições climáticas afetam a concentração corporal de $\mathrm{Na}$. As médias de temperatura e umidade relativa do ar, durante o primeiro e segundo experimentos, foram, respectivamente: 23,34 e $19,06^{\circ} \mathrm{C}$ e 72,4 e $74,5 \%$.

A composição corporal e a composição do ganho de peso em $\mathrm{Mg}$ e K foram calculadas pela equação geral (Tabela 3), obtida pela análise em conjunto dos dois experimentos. Já a composição corporal e a composição do ganho de peso em Na foram calculadas utilizando-se as equações obtidas em cada um dos experimentos. A composição do corpo vazio em $\mathrm{Mg}$, $\mathrm{K}$ e $\mathrm{Na}$ estimada a partir das equações listadas na Tabela 3, encontra-se na Tabela 4.

Os valores de concentração corporal de $\mathrm{Mg}$ nos animais com 15 e $35 \mathrm{~kg}$ de peso vivo obtidos neste trabalho foram superiores aos encontrados por Rajaratne et al. (1990), os quais variaram de 0,25 a $0,39 \mathrm{~g}$ de $\mathrm{Mg} / \mathrm{kg}$ de PCV. Já os valores de concentração corporal de $\mathrm{K}$ e Na, propostos por Annenkov (1982), são inferiores aos encontrados por esta pesquisa, no caso do potássio, e superiores no caso do sódio.

Essas diferenças nos valores de composição corporal de $\mathrm{Mg}, \mathrm{K}$ e Na entre os diversos trabalhos são
Tabela 4. Concentração de magnésio, potássio e sódio no corpo vazio e no ganho em peso corporal vazio, em ovinos Santa Inês ${ }^{(1)}$.

\begin{tabular}{|c|c|c|c|c|}
\hline \multirow{2}{*}{$\begin{array}{l}\text { Peso vivo } \\
\text { (kg) }\end{array}$} & \multirow{2}{*}{$\begin{array}{l}\text { Peso corporal } \\
\text { vazio }(\mathrm{kg})\end{array}$} & \multicolumn{3}{|c|}{ Nutriente $(\mathrm{g} / \mathrm{kg})$} \\
\hline & & Magnésio & Potássio & Sódio \\
\hline \multicolumn{5}{|c|}{ Concentração no corpo vazio } \\
\hline 15,0 & 12,9 & 0,596 & 2,929 & 1,832 \\
\hline 17,5 & 15,2 & 0,583 & 2,866 & 1,770 \\
\hline 20,0 & 17,5 & 0,572 & 2,813 & 1,719 \\
\hline 22,5 & 19,8 & 0,563 & 2,767 & 1,675 \\
\hline 25,0 & 21,2 & 0,558 & 2,742 & 1,039 \\
\hline 27,5 & 23,5 & 0,550 & 2,704 & 1,004 \\
\hline 30,0 & 25,7 & 0,544 & 2,672 & 0,974 \\
\hline 32,5 & 28,0 & 0,538 & 2,642 & 0,946 \\
\hline 35,0 & 30,2 & 0,532 & 2,616 & 0,923 \\
\hline \multicolumn{5}{|c|}{ Concentração no ganho em peso de corpo vazio } \\
\hline 15 & 12,22 & 0,521 & 2,558 & 1,465 \\
\hline 20 & 16,72 & 0,500 & 2,453 & 1,372 \\
\hline 25 & 21,23 & 0,484 & 2,376 & 1,305 \\
\hline 25 & 21,23 & 0,484 & 2,376 & 0,691 \\
\hline 30 & 26,59 & 0,470 & 2,306 & 0,641 \\
\hline 35 & 31,14 & 0,460 & 2,258 & 0,608 \\
\hline
\end{tabular}

(1) Os valores de magnésio e potássio foram calculados a partir da equação geral; os valores de sódio foram calculados para animais de 15 a $25 \mathrm{~kg}$ de peso vivo e para animais de 25 a $35 \mathrm{~kg}$ de peso vivo, a partir da equação de cada grupo.

decorrentes das diferenças existentes na proporção de ossos, músculos e gordura do corpo dos animais estudados, a qual varia em razão do tipo racial, categoria do animal, manejo alimentar, região geográfica e época do ano.

\section{Composição do ganho em peso}

As equações para predição da composição do ganho em $\mathrm{Mg}, \mathrm{K}$ e $\mathrm{Na}$ foram obtidas a partir da derivação das equações de predição da composição corporal (Tabela 3), conforme proposto por Silva (1995). As equações obtidas foram:

para o $\mathrm{Mg}$,

$\mathrm{Y}^{\prime}=0,0018 \mathrm{PCV}^{-0,131923}$;

para o $\mathrm{K}$,

$\mathrm{Y}^{\prime}=0,0089 \mathrm{PCV}^{-0,133161}$

para o Na, em animais de 15 a $25 \mathrm{~kg}$,

$\mathrm{Y}^{\prime}=0,0105 \mathrm{PCV}^{-0,209093}$;

para o $\mathrm{Na}$, em animais de 25 a $35 \mathrm{~kg}$,

$\mathrm{Y}^{\prime}=0,0194 \mathrm{PCV}^{-0,334709}$.

As estimativas da composição do ganho em peso corporal vazio, obtidas a partir destas equações, encontram-se na Tabela 4. Assim como ocorreu com a composição corporal, os valores de composição do ganho decresceram com o aumento do peso. Segundo Meyer (1988), este decréscimo no caso do K é devido principalmente ao maior acúmulo de gordura (Tabela 2) e à menor quantidade de tecido muscular dos animais mais velhos. 
As concentrações de $\mathrm{K}$ em animais com $35 \mathrm{~kg}$ de peso encontradas neste trabalho foram semelhantes às encontradas por Grace (1983), que estudou a distribuição de diversos minerais no ganho de corpo vazio de ovinos em pastejo; todavia, os valores de $\mathrm{Mg}$ desta pesquisa foram superiores, e os de $\mathrm{Na}$, inferiores.

Assim como ocorreu com a composição corporal, os valores de composição do ganho encontrados neste trabalho diferiram dos valores fixos apresentados pelo Agricultural Research Council (1988), sendo que os valores de $\mathrm{Mg}$ e $\mathrm{K}$ deste trabalho foram maiores.

Essas diferenças na composição do ganho de $\mathrm{Mg}$, $\mathrm{K}$ e Na são devidas às diferenças existentes na concentração de gordura e na proporção de ossos na carcaça dos animais estudados. Portanto, fatores que influenciem essa proporção irão alterar as concentrações corporais desses minerais.

\section{Exigências de magnésio, potássio e sódio}

As estimativas das exigências líquidas de $\mathrm{Mg}, \mathrm{K}$ e Na para o ganho de peso vivo foram calculadas dividindo-se as exigências líquidas para o ganho de peso corporal vazio (Tabela 4) pelo fator 1,10 , obtido pela equação de regressão entre o peso corporal vazio e o peso vivo (Tabela 3). Quanto às exigências líquidas de mantença, foram utilizados os valores propostos pelo Agricultural Research Council (1988).

No cálculo das exigências dietéticas, foram utilizados os valores de disponibilidade dos minerais preconizados pelo Agricultural Research Council (1988). As estimativas das exigências líquidas e dietéticas de $\mathrm{Mg}, \mathrm{K}$ e Na de cordeiros Santa Inês são apresentadas nas Tabelas 5 e 6.

Comparando as exigências líquidas de $\mathrm{Mg}$ obtidas neste trabalho, com os valores propostos pelo Agricultural Research Council (1988), observa-se que estas são 14,63\% superiores em cordeiros com $15 \mathrm{~kg}$ de peso vivo e semelhantes em animais com $35 \mathrm{~kg}$.

No caso do $\mathrm{K}$, as exigências líquidas obtidas neste trabalho são $28,9 \%$ superiores em cordeiros com $15 \mathrm{~kg}$ de peso vivo e 13,9\% superiores em animais com $35 \mathrm{~kg}$ em relação aos valores propostos pelo Agricultural Research Council (1988). Quanto ao sódio, os valores encontrados por esta pesquisa são $20,9 \%$ superiores em cordeiros com $15 \mathrm{~kg}$, e $100 \%$ inferiores em animais com $35 \mathrm{~kg}$ de peso vivo, quando comparados com os valores propostos pelo Agricultural Research Council (1988).
Tabela 5. Estimativas das exigências líquidas de magnésio, potássio e sódio para a mantença e para o ganho em peso vivo (g/animal/dia), de ovinos Santa Inês ${ }^{(1)}$.

\begin{tabular}{ccccc}
\hline \multirow{2}{*}{$\begin{array}{c}\text { Peso vivo } \\
(\mathrm{kg})\end{array}$} & Mantença $^{(2)}$ & \multicolumn{3}{c}{ Ganho diário $(\mathrm{g})$} \\
\cline { 3 - 5 } & & 100 & 200 & 300 \\
\hline & & \multicolumn{3}{c}{ Magnésio (g/animal/dia) } \\
20 & 0,045 & 0,047 & 0,094 & 0,141 \\
25 & 0,060 & 0,045 & 0,090 & 0,135 \\
30 & 0,075 & 0,044 & 0,088 & 0,132 \\
35 & 0,090 & 0,042 & 0,084 & 0,126 \\
& 0,105 & 0,041 & 0,082 & 0,123 \\
\hline \multicolumn{4}{c}{ Potássio (g/animal/dia) } \\
15 & 1,567 & 0,232 & 0,464 \\
20 & 1,790 & 0,223 & 0,446 & 0,696 \\
25 & 2,112 & 0,216 & 0,432 & 0,669 \\
30 & 2,435 & 0,210 & 0,420 & 0,648 \\
35 & 2,657 & 0,205 & 0,410 & 0,630 \\
& \multicolumn{4}{c}{ Sódio (g/animal/dia) } \\
15 & 0,387 & 0,133 & 0,266 & 0,615 \\
20 & 0,519 & 0,125 & 0,250 & 0,399 \\
25 & 0,646 & 0,063 & 0,126 & 0,375 \\
30 & 0,773 & 0,058 & 0,116 & 0,189 \\
35 & 0,901 & 0,055 & 0,110 & 0,174 \\
\end{tabular}

${ }^{(1)}$ Os valores de magnésio e potássio foram calculados a partir da equação geral; os valores de sódio foram calculados para animais de 15 a $25 \mathrm{~kg}$ de peso vivo e para animais de 25 a $35 \mathrm{~kg}$ de peso vivo, a partir da equação de cada grupo. ${ }^{(2)}$ Agricultural Research Council (1988)

Tabela 6. Estimativas das exigências dietéticas de magnésio, potássio e sódio para a mantença e para o ganho em peso vivo (g/animal/dia), de ovinos Santa Inês ${ }^{(1)}$.

\begin{tabular}{ccccc}
\hline $\begin{array}{c}\text { Peso vivo } \\
(\mathrm{kg})\end{array}$ & Mantença $^{(2)}$ & \multicolumn{4}{c}{ Ganho diário $(\mathrm{g})$} \\
\cline { 3 - 5 } & & \multicolumn{4}{c}{100} & 200 \\
15 & 0,265 & 0,278 & 0,556 & 0,834 \\
20 & 0,353 & 0,267 & 0,534 & 0,801 \\
25 & 0,441 & 0,259 & 0,518 & 0,777 \\
30 & 0,529 & 0,251 & 0,502 & 0,753 \\
35 & 0,618 & 0,246 & 0,492 & 0,738 \\
\hline & & \multicolumn{4}{c}{ Potássio (g/animal/dia) } \\
15 & 1,567 & 0,232 & 0,464 & 0,696 \\
20 & 1,790 & 0,223 & 0,446 & 0,669 \\
25 & 2,112 & 0,216 & 0,432 & 0,648 \\
30 & 2,435 & 0,210 & 0,420 & 0,630 \\
35 & 2,657 & 0,205 & 0,410 & 0,615 \\
\hline & & \multicolumn{4}{c}{ Sódio (g/animal/dia) } \\
15 & 0,425 & 0,146 & 0,292 & 0,438 \\
20 & 0,570 & 0,137 & 0,274 & 0,411 \\
25 & 0,710 & 0,130 & 0,260 & 0,390 \\
30 & 0,850 & 0,064 & 0,128 & 0,192 \\
35 & 0,990 & 0,061 & 0,122 & 0,183 \\
\hline
\end{tabular}

(1) Os valores de magnésio e potássio foram calculados a partir da equação geral; os valores de sódio foram calculados para animais de 15 a $25 \mathrm{~kg}$ de peso vivo e para animais de 25 a $35 \mathrm{~kg}$ de peso vivo, a partir da equação de cada grupo. ${ }^{(2)}$ Agricultural Research Council (1988).

Com relação às estimativas das exigências líquidas para o ganho, nota-se que existe uma grande diferença, principalmente no caso do $\mathrm{Na}$, entre os valores propostos pelo Agricultural Research Council 
(1988) e os valores obtidos neste trabalho. Essas diferenças são devidas às diferenças existentes na composição corporal dos animais utilizados, e às condições climáticas.

Com relação às exigências dietéticas totais de $\mathrm{Mg}$ obtidas neste trabalho, observa-se que estas são, aproximadamente, $21,6 \%$ maiores do que as citadas por Annenkov (1982), em cordeiros com $15 \mathrm{~kg}$ de peso vivo, com uma taxa de ganho diário de 200 g e 28,4\% menores em animais com $35 \mathrm{~kg}$.

Já as exigências dietéticas totais de $\mathrm{Na}$ obtidas neste trabalho foram 7\% maiores do que as citadas por Agricultural Research Council (1988), em cordeiros com $15 \mathrm{~kg}$ de peso vivo, com uma taxa de ganho diário de $200 \mathrm{~g}$ e 10,6\% menores em animais com $35 \mathrm{~kg}$.

Apesar das diferenças existentes entre as estimativas das exigências líquidas do ganho de $\mathrm{Na}$ e $\mathrm{K}$ deste trabalho e as estimativas do Agricultural Research Council (1988), as estimativas das exigências dietéticas totais são semelhantes. Isto ocorre porque no caso destes minerais, as exigências líquidas para o ganho representam uma pequena parcela das exigências dietéticas totais.

Como discutido anteriormente, a composição corporal e, conseqüentemente, as exigências desses minerais, irão variar, principalmente, em razão da proporção de ossos, músculos e gordura da carcaça, e qualquer fator que afete essas proporções irá afetar as exigências de $\mathrm{Mg}$, $\mathrm{K}$ e $\mathrm{Na}$.

Segundo Silva (1995), numerosas pesquisas de alimentação realizadas no Brasil, baseadas nos requerimentos nutritivos publicados em tabelas americanas ou européias, têm resultado em níveis de desempenho animal muito diferentes do esperado. Portanto, os valores de exigências preconizados pelo Agricultural Research Council (1988) e National Research Council (1985) devem ser utilizados com certas restrições, uma vez que estas tabelas foram estabelecidas utilizando-se animais diferentes e sob condições climáticas diferentes, principalmente tratando-se de ovinos deslanados, como é o caso da raça Santa Inês.

\section{Conclusões}

1. As concentrações corporais e as exigências líquidas para o ganho em $\mathrm{Mg}$, K e Na de ovinos Santa Inês em crescimento dos $15 \mathrm{~kg}$ aos $35 \mathrm{~kg}$ de peso vivo se reduzem com o aumento do peso corporal dos animais.
2. A composição corporal e as exigências líquidas para o ganho em $\mathrm{Mg}, \mathrm{K}$ e $\mathrm{Na}$ estimadas nesta pesquisa diferem dos valores fixos propostos pelo Agricultural Research Council (1988).

3. As diferenças encontradas entre os valores de tabelas estrangeiras, como o Agricultural Research Council (1988) e National Research Council (1985), e os valores observados neste trabalho refletem a necessidade de realização de novas pesquisas sobre as exigências de $\mathrm{Mg}$, $\mathrm{K}$ e $\mathrm{Na}$ de ovinos deslanados.

\section{Referências}

AGRICULTURAL RESEARCH COUNCIL (Farnham Royal, Inglaterra). The nutrient requirements of farm livestock. 3. ed. Wallingford : CAB International, 1988. $351 \mathrm{p}$.

ANDRIGUETTO, J. M.; PERLY, L.; MINARDI, I.; GEMAEL, A.; FLEMMING, J. S.; SOUZA, G. A.; BONA FILHO, A. Nutrição animal. 4. ed. São Paulo : Nobel, 1990. 395 p.

ANNENKOV, B. N. Mineral feeding of sheep. In: GEORGIEVSKII, V. I.; ANNENKOV, B. N.; SAMOKHIN, V. I. Mineral nutrition of animals. London : Butterworths, 1982. p. 321-354.

BEEDE, D. K. Mineral and water nutrition in dairy nutrition management. Veterinary Clinics of North America, Food Animal Practice, Philadelphia, v. 7, n. 2, p. 373-390, 1991.

CONRAD, J. H.; McDOWELL, L. R.; ELLIS, G. L.; LOOSLI, J. K. Minerais para ruminantes em pastejo em regiões tropicais. Campo Grande : Embrapa-CNPGC, 1985. $90 \mathrm{p}$

DAYRELL, M. S. Deficiências minerais em bovinos do Brasil. In: PEIXOTO, A. M.; MOURA, J. C.; FARIA, V. P. (Ed.). Nutrição de bovinos: conceitos básicos e aplicados. Piracicaba : FEALQ, 1993. p. 451-472.

FERREIRA, M. A.; VALADARES FILHO, S. C.; MUNIZ, E. B.; SILVA, J. F. C.; VALADARES, R. F. D.; PAULINO, M. F.; CECON, P. R. Composição corporal e exigências líquidas de macrominerais de bovinos $\mathrm{F}_{1}$ Simental x Nelore. Revista da Sociedade Brasileira de Zootecnia, Viçosa, v. 28, n. 2, p. 361-367, 1998.

GEORGIEVSKII, V. I. Mineral feeding of sheep. In: GEORGIEVSKII, V. I.; ANNENKOV, B. N.; 
SAMOKHIN, V. I. Mineral nutrition of animals. London : Butterworths, 1982. p. 321-354.

GRACE, N. D. Amounts and distribution of mineral elements associated with fleece-free empty body weight gains in the grazing sheep. New Zealand Journal of Agricultural Research, Wellington, v. 26, p. 59-70, 1983.

McDOWELL, L. R. Nutrition of grazing ruminants in warm climates. San Diego : Academic, 1985. 443 p.

MEYER, H. Potassium requirements and potassium supply in domestics animals. Animal Research and Development, Tuebingen, v. 126, p. 7-15, 1988.

NATIONAL RESEARCH COUNCIL (Washington, Estados Unidos). Nutrient requirements of domestic animals: nutrient requirements of sheep. Washington, 1985. $99 \mathrm{p}$.

NOUR, A. Y. M.; THONNEY, M. L. Minerals of carcass soft tissue and bone serially slaughtered as affected by biological type and management. Journal of Agricultural Science, Cambridge, Grã-Bretanha, v. 11, n. 1, p. 41-49, 1988.

PAULINO, M. F.; FONTES, C. A. A.; JORGE, A. M.; QUEIROZ, A. C.; SILVA, J. F. C.; GOMES JÚNIOR, P. Composição corporal e exigências em macroelementos minerais ( $\mathrm{Ca}, \mathrm{P}, \mathrm{Mg}, \mathrm{Na}$ e $\mathrm{K}$ ) de bovinos não-castrados de quatro raças zebuínas. Revista da Sociedade Brasileira de Zootecnia, Viçosa, 28, n. 3, p. 634-641, 1999.

PIRES, C. C.; FONTES, C. A. A.; GALVÃO, J. G.; QUEIROZ, A. C.; SILVA, J. F. C.; PAULINO, M. F. Exigências nutricionais de bovinos de corte em acabamento. III. Exigências de cálcio e fósforo para o ganho. Revista da Sociedade Brasileira de Zootecnia, Viçosa, v. 22, n. 1, p. 133-143, 1993.

RAJARATNE, A. A. J.; SCOTT, D.; THOMPSON, J. K.; BUCHAN, W.; PENNIE, K. The effect of variation in dietary calcium supply on the phosphorus requirements of growing lambs. Animal Production, Champaign, n. 51, p. 135-142, 1990.
RESENDE, K. T. Métodos de estimativa da composição corporal e exigências nutricionais de proteína, energia e macroelementos inorgânicos de caprinos em crescimento. Viçosa : UFV, 1989. 130 p. Tese de Doutorado.

SIGNORETTI, R. D.; SILVA, J. F. C.; VALADARES FILHO, S. C.; PEREIRA, J. C.; ARAÚJO, G. G. L.; CECON, P. R.; QUEIROZ, A. C. Composição corporal e exigências líquidas e dietéticas de macroelementos inorgânicos $(\mathrm{Ca}, \mathrm{P}$, $\mathrm{Mg}, \mathrm{K}$ e Na) de bezerros da raça Holandesa alimentados com dietas contendo diferentes níveis de volumosos. Revista da Sociedade Brasileira de Zootecnia, Viçosa, v. 28, n. 1, p. 205-213, 1999.

SILVA, D. J. Análise de alimentos: métodos químicos e biológicos. Viçosa : UFV-Imprensa Universitária, 1990. $196 \mathrm{p}$.

SILVA, J. F. C. Exigências de macroelementos inorgânicos para bovinos: o sistema ARC/AFRC e a experiência no Brasil. In: SIMPÓSIO INTERNACIONAL SOBRE EXIGÊNCIAS NUTRICIONAIS DE RUMINANTES, 1995, Viçosa. Anais... Viçosa : UFV, 1995. p. 467-504.

SILVA, J. F. C. Metodologia para determinação de exigências nutricionais de ovinos. In: SILVA SOBRINHO, A. G.; BATISTA, A. M. V.; SIQUEIRA, E. R.; ORTOLANI, E. L.; SUSIN, I.; SILVA, J. F. C.; TEIXEIRA, J. C.; BORBA, M. F. S. Nutrição de ovinos. Jaboticabal : FUNEP, 1996. p. 1-68.

SNEDECOR, G. W.; COCHRAN, W. G. Statistical methods. 6. ed. Ames : The Iowa State University Press, 1967. $593 \mathrm{p}$.

THOMPSON, J. K.; GELMAN, A. L.; WEDDELL, J. R. Mineral retention and body composition of grazing lambs. Animal Production, East Lothisn, n. 46, p. 53-62, 1988.

WILLIAMS, J. E.; WAGNER, D. G.; WALTERS, L. E. Effect of production systems on performance, body composition and lipid and mineral profiles of soft tissue in cattle. Journal of Animal Science, Champaign, v. 57, n. 4 , p. 1020-1028, 1983. 